Article abstract-Data from 694 patients hospitalized with stroke were entered in a prospective, computer-based registry. Three hundred and sixty-four patients (53 percent) were diagnosed as having thrombosis, 215 ( 31 percent) as having cerebral embolism, 70 (10 percent) as having intracerebral hematoma, and 45 (6 percent) as having subarachnoid hemorrhage from aneurysm or arteriovenous malformations. The 364 patients diagnosed as having thrombosis were divided into 233 (34 percent of all 694 patients) whose thrombosis was thought to involve a large artery and 131 (19 percent) with lacunar infarction. Many of the findings in this study were comparable to those in previous registries based on postmortem data. New observations include the high incidence of lacunes and cerebral emboli, the absence of an identifiable cardiac origin in 37 percent of all emboli, a nonsudden onset in 21 percent of emboli, and the occurrence of vomiting at onset in 51 percent and the absence of headache at onset in 67 percent of hematomas.

\title{
The Harvard Cooperative Stroke Registry: A prospective registry
}

\section{J. P. Mohr, Louis R. Caplan, John W. Melski, Robert J. Goldstein, Gary W. Duncan, J. P. Kistler, Michael} S. Pessin, and Howard L. Bleich

Many previous stroke registries ${ }^{1-10}$ and epidemiologic studies pertaining to stroke ${ }^{1-15}$ antedated both the widespread use of new diagnostic procedures, such as angiography and computerized tomography, and the recognition of new stroke syndromes, including lacunes ${ }^{16-22}$ and cerebral embolism arising from ulcerated plaques in the carotid arteries. ${ }^{23-25}$ Additionally, the larger series were limited to autopsied patients whose clinical data was collected retrospectively.

The Harvard Cooperative Stroke Registry was formed in 1972 for the prospective collection of clinical, laboratory and anatomic data from patients who were hospitalized with acute strokes. This report summarizes findings from the first 694 patients.

Methods. Five neurologists from the Massachusetts General and Beth Israel Hospitals completed questionnaires for stroke patients admitted to these hospitals since 1972. Each investigator registered personally encountered patients sequentially, regardless of why the patient was seen. Most encounters occurred through patient self-referral, for emergency admission, to a participating hospital; many patients, however, were referred for evaluation by another physician after a diagnosis of stroke.

The questionnaire consisted of 86 data items, including: initial data recorded on hospital admission, past medical history, activity at onset, speed of onset, accompanying signs, major findings on examination, cerebrospinal fluid (CSF) data, and the neurologist's initial diagnosis. The completed questionnaire was sent to the Computer Medicine Laboratory at Beth Israel Hospital, where the data were entered into a PDP-15 computer using MISAR (Miniature Information Storage and Retrieval System). ${ }^{26}$ A computer-generated summary was then returned to the neurologist for review. Additional information was then recorded concerning the hospital course, results of angiography, computerized tomography (CT) or other studies, and the neurologist's final diagnosis. Initial and final diagnoses were considered in several subcategories, including vascular pathology, abnormal vascular anatomy, brain pathology, and abnormal brain anatomy.

Diagnostic criteria continue to evolve as more is learned about stroke but those used for this study are given below.

From the Stroke Service and Neurology Service, Massachusetts General Hospital, the Beth Israel Hospital, and the Thorndike Laboratory and Department of Medicine, Beth Israel Hospital, Boston.

This study was supported by grants HS 00188 from the National Center for Health Services Research, HRA, and IF 22 NS $01970-01$ and NS 10828-01Al from the National Institutes of Health.

Presented in part at American Academy of Neurology meetings in Miami, 1975, Toronto, 1976, and Atlanta, 1977.

Accepted for publication March 23, 1978

Dr. Mohr's address is Department of Neurology, College of Medicine. University of South Alabama Medical Center, 2451 Fillingim St., Mobile, AL 36617 . 


\section{Large artery thrombosis.}

A. Clinical features. Gradual, stepwise, or stuttering stroke occurring over less than 1 week, especially with preceding transient ischemic attacks (TIAs) in the same vascular territory; evidence of large vessel occlusive disease, such as bruit, or abnormal facial pulses; history of coronary heart disease, with angina pectoris or myocardial infarction; history of peripheral vascular disease manifested by claudication or absent pulses; headache out of proportion to degree of deficit.

B. Laboratory features. CSF: Normal. CT: Bland infarction without hemorrhagic component and not confined to the territory of a single surface artery. Angiography: Occlusion or stenosis of major intracranial or extracranial vessels, such as internal or common carotid, middle, posterior, or anterior cerebral arteries, especially with stenosis and ulceration in the region of occlusion. Postmortem examination: Occlusion of large vessel with underlying atheroma and adherent clot; bland, nonhemorrhagic infarction.

\section{Lacunae.}

A. Clinical features. Abrupt or gradual onset of deficit compatible with one of the recognized lacunar entities, including pure motor hemiparesis, ${ }^{16}$ pure sensory stroke, ${ }^{17}$ crural paresis and ataxia, ${ }^{18}$ and dysarthria-clumsy hand syndrome ${ }^{19}$; absence of headache, diminished alertness, or vomiting.

B. Laboratory features. Electroencephalography (EEG): No prominent or prolonged lateralized slowing. CT: No lesion, or a small, deep infarction in the territory of a penetrating vessel. Angiography: No abnormality in the territory of the involved vessel. Postmortem examination: Small, deep cerebral infarction in the territory of a penetrating cerebral vessel, such as a lenticulostriate artery. ${ }^{21}$

\section{Embolism}

A. Clinical features. Sudden, stepwise, or fluctuating onset within 24 hours of a focal neurologic deficit, usually without TIAs in the same vascular territory, (a single TIA longer than 4 hours in the same territory would not exclude the diagnosis of embolism); a cardiac source, such as recent myocardial infarction, atrial fibrillation, valvular heart disease, or bacterial endocarditis; large-vessel arterial source manifest by bruit or abnormal ocular pulses, diminished central retinal artery pressure or other evidence of occlusive disease on funduscopic examination; systemic embolism, prior stroke or TIA in a different vascular territory.

B. Laboratory features. CSF: Absence of gross blood, red blood cells present on microscopic examination. CT: Infarction shown in the form of low-density lesion involving the superficial cerebral artery territories. Angiography: Branch occlusion of an intracerebral vessel supplying the clinically symptomatic, infarcted territory, especially when the occlusion subsequently disappears; an ulcerated plaque or stenosis or other source of embolism in a vessel proximal to the vessel supplying the infarcted territory. Postmortem examination: Hemorrhagic, superficial infarction; blockage of a distal vessel by clot without underlying atheroma, or a nonadherent clot; absence of severe stenosis or occlusion in vessels supplying an infarcted region.

\section{Intracerebral hematoma.}

A. Clinical features. Gradual onset over minutes or days or sudden onset of focal neurologic deficit, usually accompanied by signs of increased intracranial pressure, such as vomiting or diminished consciousness; hypertension or bleeding diathesis; absence of TIA or occlusive peripheral vascular disease.

B. Laboratory features. CSF: Blood corroborates the diagnosis but its absence does not exclude hematoma. CT: Focal mass of high density without use of contrast enhancement. Angiography: Mass effect without evidence of blockage of vessels. Postmortem examination: Circumscribed parenchymatous hematoma without infarction or primary involvement of the cerebral surface.

\section{Subarachnoid hemorrhage.}

A. Clinical features. Sudden onset of headache, usually accompanied by vomiting, syncope with later recovery of consciousness; subhyaloid hemorrhages on funduscopic examination.

B. Laboratory features. CSF: Bloody. CT: Blood in subarachnoid space or normal, occasionally with accompanying hydrocephalus. Angiography: Aneurysm or arteriovenous malformation with or without associated vascular spasm. Postmortem examination: Blood in subarachnoid space: aneurysm or arteriovenous malformation. 
Results. Among the 694 patients, final diagnoses included 233 patients with thrombosis of a large artery, 131 with lacunes, 215 with embolism, 70 with intracranial hematoma, and 45 with aneurysm-arteriovenous malformation. We excluded data from more than 150 additional patients, including six patients with dissecting aneurysms, two with clotting disorders, all patients studied retrospectively, and those with only TIAs or noncerebrovascular final diagnoses. In table 1, the percentages cited above are compared with those of four large previous registries, ${ }^{4-6,12}$ showing that our registry contains a higher proportion of embolism than did these earlier registries. Reclassification of our patients according to the diagnostic criteria used in previous registries, which required a cardiac source for the diagnosis of embolism, would have reduced the incidence of this diagnosis to 19 percent, increased the incidence of thrombosis to 65 percent, and rendered our final diagnoses comparable to those of the earlier registries.

Lacunes, diagnosed in 19 percent of our patients, were not clinically recognized at the time of the previous registries. The prevalence of other disorders in each subtype of stroke is presented in table 2 , and of various signs, symptoms, and laboratory findings in table 3 .

Large artery thrombosis. Ischemic strokes accounted for 569 patients, of whom 233 had strokes attributed to large artery stenosis or thrombosis due to atherosclerosis, and the remaining $336 \mathrm{had}$ strokes attributable to lacunes or embolus.

Of the thrombotic strokes, 138 occurred in the carotid territory, including 102 studied by angiography. Of these 102, 90 were initially diagnosed clinically as thrombosis, while eight were initially diagnosed as embolism and four as lacune. Angiograms showed carotid stenosis or occlusion in all 102 of the angiographically studied patients, including 13 patients who showed embolism. These 13 patients with embolism are too few to infer the sources of embolic branch occlusions, including possible carotid origin.

TIAs affected 26 percent of all patients; 65 percent of these TIAs were diagnosed as thromboses. In patients with thrombosis in the carotid territory, including those with thrombosis documented by angiogram, the occurrence of TIAs was not related to onset of the carotid stroke. Nor was there a relationship between stroke site and severity of clinical deficit, or between these features and the occurrence of TIAs, timing before stroke, or similarity of neurologic signs of TIAs and stroke.

Prior strokes had occurred in 24 percent of the patients with thrombosis, a frequency comparable to that of patients with embolism or lacunes. More patients with hypertension (blood pressure of $160 / 100 \mathrm{~mm} \mathrm{Hg}$ or greater) had thrombosis (33 percent) than any other type of stroke, but more with severe hypertension (blood pressure of 220/125 $\mathrm{mm} \mathrm{Hg}$ or greater) had hematomas (50 percent).

The onset of thrombotic stroke varied (table 4). The deficit was sudden at onset in 40 percent; stepwise or stuttering onset occurred in 34 percent. The onset was smooth or gradual in 13 percent, and fluctuated from normal to abnormal in 13 percent.

Thrombosis affected the carotid circulation in 59 percent and the vertebrobasilar circulation in 37 percent, while in 4 percent of patients the affected territory was uncertain.

Table 1. Incidence of each type of stroke in various studies

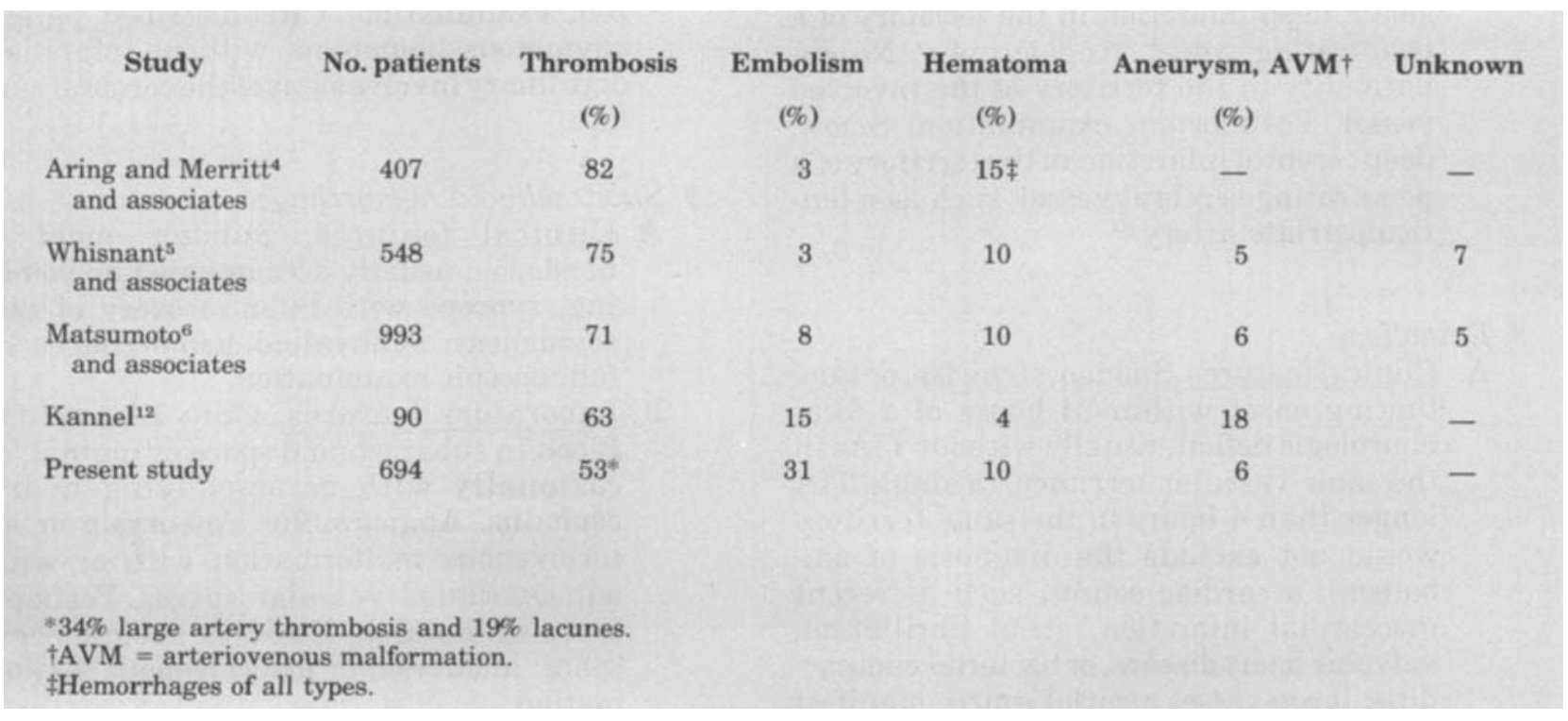


Table 2. Incidence of other disorders in each type of stroke

\begin{tabular}{|c|c|c|c|c|c|}
\hline $\begin{array}{c}\text { Disorder } \\
\text { (No. patients) }\end{array}$ & $\begin{array}{c}\text { Large artery } \\
\text { thrombosis } \\
(\%)\end{array}$ & $\begin{array}{l}\text { Lacune } \\
\text { (\%) }\end{array}$ & $\begin{array}{c}\text { Embolism } \\
\text { (\%) }\end{array}$ & $\begin{array}{c}\text { Hematoma } \\
(\%)\end{array}$ & $\begin{array}{c}\text { Aneurysm, AVM* } \\
(\%)\end{array}$ \\
\hline $\begin{array}{l}\text { Atherosclerosis } \dagger \\
\text { (255) }\end{array}$ & 56 & 37 & 34 & 11 & 5 \\
\hline $\begin{array}{l}\text { Diabetes } \\
(135)\end{array}$ & 26 & 29 & 13 & 15 & 2 \\
\hline $\begin{array}{l}\text { Hypertension } \\
\text { in the past } \\
(358)\end{array}$ & 55 & 75 & 40 & 72 & 19 \\
\hline $\begin{array}{l}\text { Hypertension } \\
\text { at onset } \ddagger \\
(401)\end{array}$ & 59 & 77 & 46 & 91 & 34 \\
\hline $\begin{array}{l}\text { Atrial } \\
\text { fibrillation } \\
\text { (103) }\end{array}$ & 8 & 5 & 34 & 6 & 2 \\
\hline $\begin{array}{l}\text { Valvular heart } \\
\text { disease } \\
\text { (78) }\end{array}$ & 8 & 5 & 25 & 3 & 0 \\
\hline
\end{tabular}

Table 3. Incidence of findings in each type of stroke

\begin{tabular}{|c|c|c|c|c|c|}
\hline $\begin{array}{c}\text { Finding } \\
\text { (No. patients) }\end{array}$ & $\begin{array}{c}\text { Large artery } \\
\text { thrombosis } \\
(\%)\end{array}$ & $\begin{array}{c}\text { Lacune } \\
(\%)\end{array}$ & $\begin{array}{c}\text { Embolism } \\
\text { (\%) }\end{array}$ & $\begin{array}{c}\text { Hematoma } \\
(\%)\end{array}$ & $\begin{array}{c}\text { Aneurysm, AVM* } \\
(\%)\end{array}$ \\
\hline $\begin{array}{l}\text { Seizure } \\
\text { (16) }\end{array}$ & 0.4 & 0 & 4 & 6 & 7 \\
\hline $\begin{array}{l}\text { Vomiting } \\
\text { (94) }\end{array}$ & 10 & 5 & 4 & 51 & 47 \\
\hline $\begin{array}{l}\text { Coma } \\
(38)\end{array}$ & 4 & 0 & 0 & 24 & 24 \\
\hline $\begin{array}{l}\text { Headache } \\
\text { preceding } \\
(47)\end{array}$ & 10 & 6 & 5 & 8 & 5 \\
\hline $\begin{array}{l}\text { Headache } \\
\text { at onset } \\
\text { (98) }\end{array}$ & 12 & 3 & 9 & 33 & 78 \\
\hline $\begin{array}{l}\text { Headache } \\
\text { later } \\
(64)\end{array}$ & 9 & 2 & 11 & 19 & 31 \\
\hline $\begin{array}{l}\text { Bloody CSF } \dagger \\
\text { (70) }\end{array}$ & 0 & 2 & 1 & 70 & 94 \\
\hline $\begin{array}{l}\text { TIA } \\
\text { (175) }\end{array}$ & 50 & 23 & 11 & 8 & 7 \\
\hline
\end{tabular}


Table 4. Onset for each type of stroke

\begin{tabular}{|c|c|c|c|c|c|}
\hline Onset & $\begin{array}{c}\text { Large artery } \\
\text { thrombosis } \\
(\%)\end{array}$ & $\begin{array}{c}\text { Lacune } \\
(\%)\end{array}$ & $\begin{array}{c}\text { Embolism } \\
(\%)\end{array}$ & $\begin{array}{c}\text { Hematoma } \\
(\%)\end{array}$ & $\begin{array}{c}\text { Aneurysm, AVM* } \\
(\%)\end{array}$ \\
\hline Sudden & 40 & 38 & 79 & 34 & 80 \\
\hline $\begin{array}{l}\text { Stepwise or } \\
\text { stuttering }\end{array}$ & 34 & 32 & 11 & 3 & 3 \\
\hline $\begin{array}{l}\text { Smooth or } \\
\text { gradual }\end{array}$ & 13 & 20 & 5 & 63 & 14 \\
\hline Fluctuations & 13 & 10 & 5 & 0 & 3 \\
\hline
\end{tabular}

In patients with thrombotic stroke involving the carotid artery, bruits and low central retinal artery pressures tended to occur together. Of 69 patients examined for both features, 22 had both an ipsilateral low central retinal artery pressure and a bruit and 30 had neither; only eight had a bruit alone, and nine had an abnormal pressure alone ( $p<0.001$ for independence of pressure and bruit by chi square with a $2 \times 2$ table). Considering all patients with thrombosis, bruit and low central retinal artery pressure occurred in 24 percent and 32 percent, respectively, compared with bruit and low central retinal artery pressure in 10 percent and 14 percent of patients with lacunes, in 9 percent and 11 percent of patients with embolism, and in 1 percent and 3 percent of patients with hemorrhage.

In ischemic (thrombotic and embolic) strokes in the carotid territory, angiographic findings in 210 patients were compared with clinical state at the time of discharge. Of the 32 patients with normal angiograms, 75 percent had a mild clinical deficit. Of the 178 patients with angiographic abnormalities, only 53 percent had a mild deficit ( $p<0.04$; chi square).

No patient with thrombotic stroke showed all of the classical features. Of 233 thrombotic strokes (138 in the carotid territory), TIAs were present in 49 of the 75 diagnosed by angiogram. In 28 of these 49 , the TIAs were typical of the subsequent stroke. Nine of the 49 had a purely motor deficit, and none of these had a stepwise onset.

Embolism. Cerebral embolism was diagnosed in 215 of the 694 patients. This comparatively high incidence (31 percent) may represent investigator bias or population peculiarities, but we suspect that embolism is actually common. Because of the difficulties in differentiating embolism from lacune or thrombosis in some instances, the data from patients whose diagnosis was documented by angiogram were analyzed separately.

Angiography was performed in 106 of the 215 patients with cerebral embolism, CT was done in 49 , and autopsy in six. In the 88 patients with angiograms that were completely described, $52(60$ percent) had embolic arterial occlusions in the clinically affected territory, and 11 of these had additional findings of stenosis, plaque, or occlusion of the ipsilateral carotid artery. In the 36 patients without embolic arterial occlusion on angiogram, 22 showed atheromatous change in the carotid artery ipsilateral to the stroke, one had an early draining vein, one had an aneurysm, and 12 had had normal angiograms.

Timing of angiography after the stroke was important. When dates were available, the data showed that 38 of 52 angiograms ( 73 percent) done within 2 days of the stroke were positive for emboli, whereas only eight of 29 studies ( 28 percent) performed after the second day showed emboli ( $p<0.001$; chi square).

There was no significant difference between the 52 patients in whom angiography demonstrated embolic occlusion and the 35 patients in whom it did not, with respect to speed of onset, occurrence of coma, aphasia, seizures, infarction of any single cerebral lobe, clinical severity, or death in the hospital. Therefore, the clinical features of all 215 patients with a discharge diagnosis of embolism were treated together in analyzing the data.

The sites of emboli in the brain were not random. The middle cerebral artery territory was involved by clinical evidence in 75 percent of all patients with embolism and in 66 percent of those with angiograms. The posterior cerebral artery territory was affected in 11 percent, the basilar artery territory in 5 percent; and the anterior cerebral artery territory in 3 percent. Among 75 middle cerebral arterial strokes, the left side was affected in 58 percent; the main stem was occluded in 26 patients, the upper division in nine, branches beyond the upper division in 22 , the lower division in eight, a lower division branch in one, unspecified parts of the middle cerebral artery in six, and other 
arteries in addition to the middle cerebral in three.

The onset was sudden, with deficit maximal at onset, in 79 percent of embolic strokes, compared with 53 percent in strokes of other types (table 4). Other types of onset were far less common; stepwise or stuttering occurred in 10 percent, smooth or gradual onset in 6 percent, and fluctuation from normal to abnormal in 5 percent.

There were cardiac risk factors (atrial fibrillation, valvular heart disease, or recent myocardial infarction) in 170 patients ( 25 percent of all strokes); 112 of which were diagnosed as cerebral embolism. Cardiac risk factors proved helpful in predicting the findings of angiography $(p<0.01$; chi square for a table with or without cardiac risk factor versus embolus or no embolus on angiogram), but atrial fibrillation as a single risk factor alone showed less effect $(p<0.2$; chi square). Atrial fibrillation occurred in 103 patients ( 15 percent of all strokes) and 73 of these were diagnosed as embolic strokes. Duration of the fibrillation varied, from 8 years before the embolism to onset after hospital admission.

Many features usually considered helpful in the diagnosis of embolism proved to be infrequent. Evidence of systemic embolism was present in 14 patients ( 2 percent of all strokes), and 12 of these were considered to have embolic strokes. Valvular heart disease was present in 78 patients (11 percent of strokes) and was associated with cerebral embolism in 51.

In five of the 46 stroke patients with Wernicke aphasia, there was no other neurologic deficit. Although embolism was the initial diagnosis in all five of these patients, three were later found to have hematomas. Anticoagulation was undertaken in two of the patients with hematoma before the correct diagnosis was established.

Headache with embolic stroke occurred in 9 percent of patients, a frequency similar to headache in large artery thrombosis. No single artery was particularly associated with headache. In patients with emboli in the middle cerebral artery territory, headache occurred with equal frequency among infarcts owing to occlusion of the stem, major division, or a branch of the artery. Headache did not predict the extent of ultimate deficit.

The inferred source of embolism did not reliably predict the clinical prodrome, syndrome, or severity of deficit. The patients with angiograms ( 88 in all) whose source was considered to be cardiac, carotid, or unknown did not differ from each other with regard to prior TIAs, clinical pattern of TIAs, initial clinical deficit, or severity at discharge.

Physicians' behavior was reflected in the selection of patients for angiography; this selection was undertaken more often in patients initially diagnosed as having embolism without an evident cardiac source than in patients with a cardiac source. Thus, 72 of 109 (65 percent) patients without a cardiac source of embolism were studied, as opposed to only 37 of 111 (33 percent) with a cardiac source $(p<0.001$; chi square). The latter 37 included 14 patients with recent myocardial infarction considered a source for embolism. The patients in both the angiogram and nonangiogram groups initially diagnosed as having embolism did not otherwise differ in sex, history of prior stroke, TIAs, hypertension, early clinical course, presence of systemic embolism, or CSF.

Therapy was much influenced by the angiographic findings. Among patients with angiograms, anticoagulants were given in 39 of 49 with embolism of either cardiac or noncardiac sourcealmost twice as often as anticoagulants were given in the nonangiogram group with a cardiac source (38 of 86 anticoagulated), and almost four times as often as these agents were administered in the nonangiogram group without a cardiac source (9 of 41 anticoagulated). Other data, such as clinical findings, aphasia, mode of onset, et cetera revealed no significant differences in the predictability of angiographic findings between patients with and without a cardiac source of embolism. Of the $10 \mathrm{pa}-$ tients with embolism documented by angiogram and not treated with anticoagulants, three underwent ipsilateral carotid endarterectomy for what was considered the source of cerebral embolism; because of the severity of the clinical deficit, the other seven were not treated.

The outcome in patients with embolism was generally predicted by the severity of the initial clinical deficit, but not by the site of the occlusion. Three of the 26 patients with embolism involving the stem of the middle cerebral artery experienced almost complete remission within 6 months.

No single patient experienced all of the classical features of cerebral embolism. Among the 215 patients with a discharge diagnosis of cerebral embolism, angiography was performed in 106 and was abnormal in 52. Of these 52, 41 experienced maximal deficit at onset, with a cardiac source in 18. Ten had a carotid-artery-territory stroke, aphasia, or a nondominant hemisphere syndrome and atrial fibrillation, but no previous TIA. Eight had the onset during activity, one with headache, and none had systemic embolism.

Hemorrhage. One hundred and fifteen strokes (17 percent) were due to hemorrhage, with 70 (61 percent) being primary parenchymatous, so-called hypertensive, hematoma. Admission diastolic blood pressure exceeded $100 \mathrm{~mm} \mathrm{Hg}$ in 63 of these patients. Parenchymatous hemorrhages had predilections for certain brain areas, most frequently the putamen ( 33 of 67 patients).

The state of consciousness on admission closely paralleled the outcome: The less conscious the patient, the worse the outlook, and no patient admitted in coma survived. However, of patients with cerebellar hemorrhage, five of eight were alert on 
admission, two were lethargic, only one stuporous, and none comatose; yet two died and three had moderate or severe deficit at discharge.

The onset of parenchymatous hematomas, regardless of site, was smooth and gradual in 63 percent, maximal at onset in 34 percent, and marked by stuttering in 3 percent. None experienced a fluctuating onset. After admission, 56 percent experienced further worsening, and 25 percent of these deteriorated suddenly. Repeated ('T showed no increase in the size of the hematoma after the patient became worse.

()f the 54 patients sufficiently alert to be interviewed, 33 percent reported headache at onset, and only 42 percent had headache at any time. Stiff neck occurred in only 17 percent of those alert enough to be interviewed. Vomiting occurred in 51 percent, including all seven cerebellar hematomas.

Eye movement disorders were helpful in localizing the hematoma. Deviation of conjugate horizontal gaze occurred in 5: percent of patients with putaminal hematoma; however, 30 percent had no impairment of eye movements despite a motor deficit varying from mild paresis to hemiplegia. In patients with thalamic hematoma, a variety of ocular motility disturbances occurred: paralysis of upward gaze in three patients, deviation of conjugate gaze in one, skew deviation in three, and total immobility in one comatose patient. Two patients showed no impairment. In patients with large hematomas, abnormal eye movements were not helpful in differentiating putaminal from thalamic hematomas.

There were no characteristic pupillary abnormalities in patients with cerebellar hematoma. In putaminal hematoma, 10 of 33 patients had abnormal pupils, each demonstrating asymmetry and at least one nonreactive pupil. Eight of these 10 died. Small, poorly reactive pupils were more common in thalamic hematoma (eight of 11 ) and four of these eight died.

An important therapeutic implication was noted in the diagnostic confusion of embolism and hematoma. Ten of 214 initial diagnoses of embolism were changed to hematoma, and three of 59 hematoma diagnoses were changed to embolism. The changes were based on ('T or angiography.

Data on aneurysm and arteriovenous malformation are omitted because these disorders affected only 45 patients $(6$ percent .

Lacunes. Patients with signs consistent with previously described syndromes of small, deep cerebral and brainstem infarctions labeled lacunes constituted 19 percent of the final diagnoses. (Of these 131 patients, the initial diagnosis was lacune in 89 percent. ( ) n the basis of angiography, nine diagnoses of thrombotic strokes were changed to lacunes and 13 diagnoses of lacunes were changed to thrombosis. On the basis of ( $\mathrm{CT}$, four hematomas were changed to lacunes, and two lacunes were changed to hematomas. Lacunes and subarachnoid hemorrhages were never misdiagnosed for one another.

Lacunes were diagnosed on clinical grounds alone more often ( 69 percent) than any other stroke (embolism, 40 percent; thrombosis, 36 percent; hematoma, 23 percent; subarachnoid hemorrhage, 9 percent , and were diagnosed least often by autopsy. Pure motor stroke was the most frequent lacunar syndrome diagnosed 163 patients).

Onset in lacunes more closely approximated that of thrombosis than any other major etiology (table 4).

With increasing awareness of basilar branch infarcts, 42 percent of the lacunes were assigned a vertebrobasilar site. ${ }^{27}$

Patients with lacunar or thrombotic strokes had about the same prevalence of prior stroke and the same lack of atrial fibrillation and valvular heart disease. Hypertension was more often present in those with lacunes ( 75 percent) or hematoma 172 percent) than with thrombosis ( 55 percent), and systemic atherosclerosis was more often evident in thrombosis 156 percent) than in lacunes ( 37 percent) or embolism (34 percent). Patients with lacunar strokes experienced less than half as many TIAs as did those with thrombosis. Among the 19 patients with lacunes studied by angiography, none had embolic occlusions. The incidence of normal angiograms was 4 percent in patients with thrombosis, compared to 63 percent in patients with lacunar strokes.

Discussion. Previous stroke registries were used to study the clinical characteristics of subtypes of stroke to allow more accurate clinical diagnosis. Dalsgaard-Nielsen ${ }^{1.2}$ examined the relationship between clinical and postmortem diagnosis in all autopsied cases of cerebral apoplexy at one hospital from 1940) through 1953. () 239 strokes clinically diagnosed as hemorrhage, only 155 (65 percentl were confirmed at autopsy. (Of 139 strokes clinically diagnosed as thromboembolism, only 81 158 percent) were confirmed. Dalsgaard-Nielsen enumerated the frequency of clinical characteristics that might allow differentiation between hemorrhage and thromboembolism.

Aring ${ }^{3}$ and, earlier, Aring and Merritt ${ }^{4}$ analyzed the clinical characteristics of 245 patients with stroke during the period 1925 through 1935 . These studies were also retrospective and included only autopsied cases. Table 5 compares the frequency of findings in the present study with those of Aring and Dalsgaard-Nielsen. The incidence of coma was higher in all subgroups in the previous studies, perhaps because those studies included only fatal cases. In our study, headache at onset and vomit- 
Table 5. Frequency of clinical features in each type of stroke in various studies

\begin{tabular}{|c|c|c|c|c|c|c|c|c|c|c|}
\hline \multirow[b]{2}{*}{ Feature } & \multicolumn{3}{|c|}{ Thrombosis } & \multicolumn{2}{|c|}{ Embolism } & \multicolumn{2}{|c|}{ Hematoma } & \multirow[b]{2}{*}{$\begin{array}{c}\text { Dalsgaard- } \\
\text { Nielsen } \ddagger\end{array}$} & \multicolumn{2}{|c|}{ Aneurysm, AVM* } \\
\hline & $\begin{array}{c}\text { Present } \\
\text { study } \S\end{array}$ & $\underset{\text { (3) }}{\text { Aring }}$ & $\begin{array}{c}\text { Dalsgaard- } \\
\text { Nielsen } \dagger\end{array}$ & $\begin{array}{r}\text { Present } \\
\text { study }\end{array}$ & Aring & $\begin{array}{l}\text { Present } \\
\text { study }\end{array}$ & Aring & & $\begin{array}{l}\text { Present } \\
\text { study }\end{array}$ & Aring \\
\hline Coma & 15 & 32 & 30 & 11 & 22 & 42 & 51 & 71 & 71 & Uncommon \\
\hline Seizures & 0.3 & 8 & & 4 & 9 & 7 & 14 & & 7 & Rare \\
\hline $\begin{array}{l}\text { Headache } \\
\text { at onset }\end{array}$ & 9 & 4 & & 8 & 36 & 36 & 23 & & 81 & $\begin{array}{l}\text { Very } \\
\text { severe }\end{array}$ \\
\hline Vomiting & 9 & 4 & & 8 & 22 & 44 & 22 & & 52 & Common \\
\hline $\begin{array}{l}\text { Bloody cerobro- } \\
\text { spinal fluid }\end{array}$ & 0.8 & 0 & 0 & 4 & 15 & 60 & 73 & 67 & 92 & 100 \\
\hline
\end{tabular}

ing were much less common in patients with embolism, whereas they were more common in patients with intracerebral hematoma. Data concerning seizures and bloody CSF were comparable.

In addition to delineating clinical characteristics, stroke registries have been used to ascertain the frequency of the common stroke subtypes. Moderate variations are noted between our data and those of others. ${ }^{1-6,11,12}$ All of the autopsy series gave a considerably greater frequency of intracerebral hematoma. The incidence of subarachnoid hemorrhage was relatively uniform except in the Framingham Study, in which patients with bloody CSF may have been labeled as having subarachnoid hemorrhage, since there were fewer patients with intracerebral hematoma and more with subarachnoid hemorrhage.

The incidence of cerebral embolism was far higher in our series than in all others. When stated, the criteria for cerebral embolism in the other series required a clear cardiac source, whereas we included other patients. Matsumoto and associates" reported that "the percentage of strokes attributed to embolic infarction ( 8 percent) is undoubtedly understated because it includes only cases in which a source for an embolus was recognized." Millikan and associates ${ }^{28}$ differentiated emboli from the heart, in which there is "extraordinarily sudden development of focal neurological symptoms and signs. . . within seconds or at most a few minutes," and intraarterial emboli from a plaque in a proximal great vessel, in which "the temporal profile of the clinical events may be variable from quite swift (many seconds to a few minutes) to hours." If thrombotic and embolic strokes in our study were pooled, the resulting category of thromboembolism (all nonhemorrhagic strokes) would be 84 percent, a figure similar to that for combined thromboembolism in the other studies. The postmortem series from the Nationwide Cerebrovascular Disease Mortality Study ${ }^{11}$ contained few patients diagnosed as having thrombotic stroke, but there were many cases with unclassified cerebrovascular disease in whom no hemorrhage was found, presumably also cases of thromboembolism. In our series, 21 percent of the patients with cerebral embolism did not have a sudden deficit maximal at onset, and three patients with cerebral embolism from known subacute bacterial endocarditis had a stepwise onset. Fisher ${ }^{29}$ observed that, on occasion, emboli produce a nonsudden deficit, and we believe that the incidence of intraarterial embolization is considerably higher than previously recognized.

Registries can also be used to study the diseases associated with stroke. The Framingham Study ${ }^{12-14}$ emphasized the key role of hypertension in both hemorrhagic and nonhemorrhagic stroke. Heart disease was also a contributing factor, even when the data were corrected for hypertension. In our study, hypertension, heart disease, and atherosclerosis (defined as the presence of past myocardial infarction, angina pectoris, claudication, bruit, or absent peripheral pulses), were common in patients with thromboembolic stroke (table 2).

Finally, stroke registries can be used to study prognosis. Feigenson and associates, ${ }^{30,31}$ at the Burke Rehabilitation Center in White Plains, New York, studied 566 patients to uncover factors predicting outcome and length of stay. Stern, Lincoln and Robinson ${ }^{10}$ used computer-generated discharge summaries of stroke patients at a rehabili- 
tation hospital to study prognostic factors and patient care. Steinberg ${ }^{9}$ also analyzed admissions to a rehabilitation hospital with prognostic guidelines in mind.

Our study provides data on patients seen at hospitals known for interest in stroke. Frequency estimates derived from our data are neither population-based nor epidemiologically sound; they may not be representative of other geographic areas, of other hospitals in the same area, or patients seen by other consultants within the same hospitals, of those not seen in consultation, of those not admitted for stroke, or of those not known to have had a stroke. Nevertheless, our population may constitute a particularly useful study group. Studies of patients whose strokes go unrecognized, who are never referred for consultation, or who survive acute episodes, such as patients admitted to a rehabilitation hospital, are biased in the direction of survival, whereas studies based on autopsy are biased in the direction of death. The intermediate group, in whom proper intervention may make a difference, merits special interest.

Data in the current registry allowed strokes to be examined on a large-scale basis. We hope that detailed, long-term follow up of these patients using a standardized telephone interview will increase our understanding of the variety of syndromes subserved under the general term stroke.

\section{References}

1. Dalsgaard-Nielsen T: Survey of 1000 cases of apoplexia cerebri. Acta Psychiatr Neurol Scand 30:169-185, 1955

2. Dalsgaard-Nielsen T: Some clinical experience in the treatment of cerebral apoplexy ( 1000 cases). Acta Psychiatr Neurol Scand (Suppl) 108:101-119, 1956

3. Aring CD: Differential diagnosis of cerebrovascutar stroke. Arch Intern Med 113:195-199, 1964

4. Aring $\mathrm{CD}$, Merritt $\mathrm{HH}$ : Differential diagnosis between cerebral hemorrhage and cerebral thrombosis. Arch Intern Med 56:435-456, 1935

5. Whisnant JP, Fitzgibbons JP, Kurland LT, et al: Natural history of stroke in Rochester, Minnesota, 1945 through 1954. Stroke 2:11-22, 1971

6. Matsumoto N, Whisnant JP, Kurland LT, et al: Natural history of stroke in Rochester, Minnesota, 1955 through 1969: An extension of previous study, 1945 through 1954. Stroke 4:20-29, 1973

7. Harmsen P, Tibblin G: A stroke registry in Goteborg, Sweden. Acta Med Scand 191:463-470, 1972

8. Steinberg FU: A pilot stroke registry in a general hospital. Gerontologist 12:148-150, 1972
9. Steinberg FU: The stroke registry: A prospective method of studying stroke. Arch Phys Med Rehabil 54:31-35, 1973

10. Stern PH, Lincoln JC, Robinson MB: Data base for stroke rehabilitation using computerized English text discharge summaries. Stroke 6:181-187, 1975

11. Kullar LH, Bolker A, Saslow MS, et al: Nationwide cerebrovascular disease mortality study. Am J Epidemiol 90:567-578, 1969

12. Kannel WB, Dawber TR, Cohen MS, et al: Vascular disease of the brain-epidemiologic apsects: The Framingham study. Am J Public Health 55:1355-1366, 1965

13. Kannel WB, Wolf PA, Verter J, et al: Epidemiologic assessment of the role of blood pressure in stroke: The Framingham study. JAMA 214:301-310, 1970

14. Wolf PA, Kannel WB, McNamara PM, et al: The role of impaired cardiac function in atherothrombotic brain infarction: The Framingham study. Am J Public Health $63: 52.58,1973$

15. Kannel WB: Current status of the epidemiology of brain infarction associated with occlusive arterial disease. Stroke $2: 295-318,1971$

16. Fisher CM, Curry HB: Pure motor hemiplegia of vascular origin. Arch Neurol 13:30-44, 1965

17. Fisher CM: Pure sensory stroke involving face, arm and leg. Neurology (Minneap) 15:76-80, 1965

18. Fisher CM, Cole M: Homolateral ataxia and crural paresis: A vascular syndrame. J Neurol Neurosurg Psychiatry 28:48-55, 1965

19. Fisher CM: A lacunar stroke: The dysarthria-clumsy hand syndrome. Neurology (Minneap) 17:614-617, 1967

20. Fisher CM: Lacunes: Small, deep cerebral infarcts. Neurology (Minneap) 15:774-784, 1965

21. Fisher CM: The arterial lesions underlying lacunes. Acta Neuropathol (Berl) 12:1-15, 1969

22. Caplan LR: Lacunar infarction: A neglected concept. Geriatrics 31:71-75, 1976

23. Wood EH, Correll JW: Atheromatous ulceration in major neck vessels as a cause of cerebral embolism. Acta Radiol 9:520-536, 1969

24. Chase NE: Radiographic diagnosis of the ulcerated atherosclerotic plaque. In McDowell FH, Brennan RW (Editors): Eighth Conference of Cerebral Vascular Disease. New York, Grune \& Stratton, 1973, pp 253-257

25. Eisenberg RL, Nemzek WR, Moore WS, et al: Relationship of transient ischemic attacks and angiographically demonstrable lesions of the carotid artery. Stroke 8:483-486, 1977

26. Karpinski RH, Bleich HL: MISAR: A miniature information storage and retrieval system. Comput Biomed Res 4:655-660, 1971

27. Fisher CM, Caplan LR: Basilar artery branch occlusion: A cause of pontine infarction. Neurology (Minneap) 21:900905,1971

28. Millikan CH, Bauer RB, Goldschmidt J, et al: A classification and outline of cerebrovascular disease: II. Stroke 6:565-616, 1975

29. Fisher CM, Pearlman A: The nonsudden onset of cerebral embolism. Neurology (Minneap) 17:1025-1032, 1967

30. Feigenson JS, McDowell FH, Meese PD, et al: Factors influencing outcome and length of stay in a stroke rehabilitation unit: Part 1. Stroke 8:651-656, 1977

31. Feigenson JS, McCarthy ML, Greenberg SD, et al: Factors influencing outcome and length of stay in a stroke rehabilitation unit: Part 2. Stroke 8:657-662, 1977 


\section{Neurology}

The Harvard Cooperative Stroke Registry: A prospective registry

J. P. Mohr, Louis R. Caplan, John W. Melski, et al.

Neurology 1978;28;754

DOI 10.1212/WNL.28.8.754

This information is current as of August 1, 1978

Updated Information \&

Services

Citations

Permissions \& Licensing

Reprints including high resolution figures, can be found at: http://n.neurology.org/content/28/8/754.full

This article has been cited by 79 HighWire-hosted articles: http://n.neurology.org/content/28/8/754.full\#\#otherarticles

Information about reproducing this article in parts (figures,tables) or in its entirety can be found online at:

http://www.neurology.org/about/about_the_journal\#permissions

Information about ordering reprints can be found online:

http://n.neurology.org/subscribers/advertise

Neurology $\circledR^{\circledR}$ is the official journal of the American Academy of Neurology. Published continuously since 1951, it is now a weekly with 48 issues per year. Copyright $(\odot 1978$ by the American Academy of Neurology. All rights reserved. Print ISSN: 0028-3878. Online ISSN: 1526-632X.

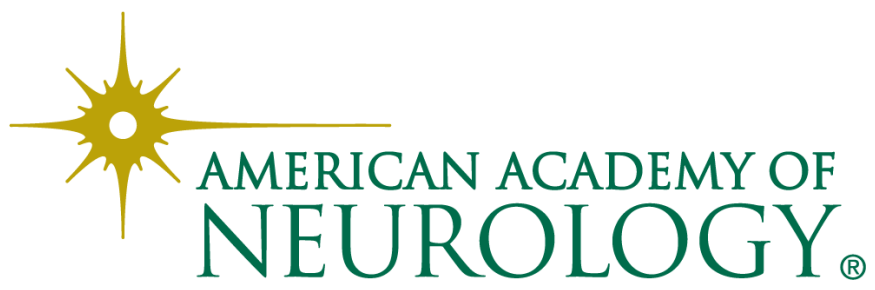

